\title{
Modelo explicativo para intenção de uso de serviços de fintechs: a perspectiva dos consumidores brasileiros das gerações $Y$ e $Z$
}

\author{
Caio Bernardo Santos Almeida - caiobernardoalmeida02@gmail.com ${ }^{1}$ \\ Marley Rosana Melo de Araújo - marleymeloaraujo@gmail.com ${ }^{1}$ \\ Maria Conceição Melo Silva Luft - ceicamelo.ufs@gmail.com ${ }^{1}$
}

Resumo - Este estudo objetivou verificar a influência de atributos do indivíduo referentes à inovação e de variáveis perceptivas sobre a intenção de uso de serviços de fintechs, por consumidores brasileiros das gerações Y e Z, usuários e não usuários dessas startups. Após adequação teórica ao contexto brasileiro (back translation, análises semântica e de juízes) e adaptação de itens do instrumento de Chauhan, Yadav e Choudhary (2019), 297 indivíduos responderam-no em um survey online. O modelo teórico da pesquisa foi testado no software AMOS v.22, pela técnica Path Analysis e, após poucos ajustes, apresentou $62 \%$ de poder explicativo da intenção de uso. Domínio da Inovação Específica influencia a percepção de utilidade e de facilidade de uso de fintechs $(\beta=0,51, \mathrm{p}$ $<0,001$ para ambos). Por sua vez, estes dois indicadores de percepção são os que mais influenciam na intenção de uso de serviços de fintechs, prevalecendo a contribuição explicativa de Utilidade Percebida $(\beta=0,35, \mathrm{p}<0,001)$.

Palavras-chave: Fintech. Inovação. Intenção de uso. Gerações Y e Z.

\section{Explanatory model for intention to use fintech services: the perspective of brazilian consumers of generations $\mathrm{Y}$ and $\mathrm{Z}$}

\begin{abstract}
This study aimed to verify the influence of individual attributes related to innovation and perceptual variables on the intention of using fintech services, by Brazilian consumers of generations $\mathrm{Y}$ and $\mathrm{Z}$, users and non-users of these startups. After theoretical adaptation to the Brazilian context (back translation, semantic and judges' analyzes) and adaptation of the instrument items by Chauhan, Yadav, and Choudhary (2019), 297 individuals answered it in an online survey. The theoretical model of the research was tested in the AMOS v.22 software, using the Path Analysis technique and, after few adjustments, presented $62 \%$ of explanatory power of the intention to use it. Domain of Specific Innovation influences the perception of utility and ease of use of fintechs $(\beta=0,51, p<0,001$ for both). Therefore, these two perception indicators are the ones that most influence the intention to use fintech services, with the explanatory contribution of Perceived Utility prevailing $(\beta=0,35$, $\mathrm{p}<0,001)$
\end{abstract}

Keywords: Fintech. Innovation. Intention to use. Generations Y and Z.

Data da Submissão: 22/12/2020

Data de aceitação: 11/03/2021 


\section{Introdução}

Com a proliferação dos sistemas de informação, comunicação e tecnologia (ICT), os impactos advindos dessas mudanças têm sido percebidos nos vários âmbitos de negócios. Um setor que tem apresentado constantes mudanças, em função dessa evolução dos serviços baseados na internet, é o financeiro, principalmente, nos últimos anos, com o surgimento de um novo modelo de negócios chamado fintech, que tem causado discussões tanto no mundo (HU; DING; LI; CHEN: YANG, 2019), como no Brasil.

Fintech é um termo emergente que descreve, principalmente, os setores de tecnologia financeira em uma ampla gama de operações para organizações, visando a melhoria da qualidade do serviço pelo uso de aplicativos de tecnologia da informação (GAI; QIU; SUN, 2018). Fintech é uma tecnologia digital com block chain, big data e consultoria de investimento inteligente em seu cerne, e é amplamente utilizada para ampliar as áreas de serviços financeiros. Tratam-se de novas ferramentas que usam tecnologias emergentes de informação, como Internet das Coisas, tecnologia móvel e computação em nuvem (HU et al., 2019).

As principais características das fintechs vão desde um avanço considerável da tecnologia da informação e comunicação, na constante busca por inovação, e o uso da tecnologia como sua aliada estratégica, à uma atuação voltada para o público sub-atendido (ABFINTECHS; PWC 2018). Esse contínuo desenvolvimento impacta na criação de novos modelos de negócio, cada vez mais centrados na geração de valor diferenciado para o cliente e para os novos players de mercado no segmento de produtos bancários (JORGE et al., 2018). Adicionalmente, isso demonstra como as tecnologias digitais estão provocando alterações no setor, que é altamente regulamentado, a exemplo do surgimento de sistemas de pagamento e de trocas monetárias não tradicionais, provocando um aumento da turbulência nos mercados de moeda e desafiando os fundamentos desse sistema financeiro, até então já consolidado (GOMBER et al., 2017).

Percebe-se que as mudanças no setor bancário, assim como nos outros setores, continuam acontecendo. $\mathrm{O}$ setor vem se aperfeiçoando ao longo dos anos, promovendo alternativas que diminuam a quantidade de clientes em busca de atendimento em suas agências físicas. A oferta de serviços em tempo integral, a exemplo dos terminais eletrônicos, configura a inserção das tecnologias de forma efetiva nesse setor (FRIÓSI et al., 2017). A importância que a internet vem ganhando na sociedade e o aumento do acesso dos consumidores às tecnologias de informação e comunicação (TICs), como os smartphones, em diversos países do mundo, têm contribuído para o surgimento das Financial Technology - Fintechs (FINTECHLAB, 2017).

Ao contrário dos bancos, que oferecem aos consumidores três principais serviços financeiros (depósito, pagamento e empréstimos), algumas empresas fintech estão mais focadas em fornecer aos clientes uma melhor experiência de uso em um nicho. Como empresas tradicionais de serviços financeiros, os bancos entendem a importância das experiências do usuário, e alguns deles começaram a melhorar sua competitividade e compartilhamento de mercado, adquirindo ou cooperando com empresas fintech. Segundo dados da empresa de consultoria americana Accenture, de 2010 a 2016, o investimento global em fintech aumentou de 12,2 bilhões de dólares para 153,1 bilhões de dólares, um aumento de quase 12 vezes (HU et al., 2019).

No Brasil, pode-se dividir o mundo das fintechs em 10 grandes grupos, sendo eles: pagamentos e transferências, gestão financeira empresarial, crédito, crowfunding, criptomoedas, seguros, identidade, investimentos, banco digital e planejamento de finanças pessoais (JORGE 
et al., 2018). Desse modo, nesse panorama dos grupos das fintechs, coexistem tanto as áreas com um mercado bem consolidado, como novas áreas. Apesar do crescimento, especialização e difusão global das fintechs, há poucos estudos sobre o mecanismo de influência por trás da adoção de serviços de fintechs por consumidores e clientes de bancos (HU et al., 2019). Dessa forma, o papel inovador, transformador, disruptivo e inclusivo das tecnologias financeiras carece de estudo e entendimento de seus eventuais riscos e benefícios (OLIVEIRA; DESIDÉRIO, 2018), a fim de subsidiar o melhor posicionamento comercial desse novo modelo de negócios.

Pode-se afirmar que as fintechs estão correspondendo, principalmente, às demandas das gerações que estão ingressando no mercado financeiro, gerações Y (Millennials) e Z (Digital Natives), que constitui a maioria dos usuários dessas empresas startups (HU et al., 2019). Estas gerações são responsáveis, em sua maioria, pelo aumento do consumo das TICs, além de suscitarem uma pressão por redução de custos, devido à mudança de perfil dos usuários dos produtos e à faixa etária em que se encontram, ocasionando a progressiva digitalização dos serviços financeiros e impulsionando a recente revolução tecnológica no setor (GAI; QIU; SUN, 2018; OLIVEIRA; DESIDÉRIO, 2018). Hu et al. (2019) ponderam que os Millennials são menos capazes financeiramente que as pessoas mais velhas, portanto, esta geração não é, atualmente, grande usuária de bancos tradicionais. No entanto, com o passar do tempo, a capacidade financeira da geração Millennials vai se fortalecer gradualmente, e eles provavelmente se tornarão os principais usuários do segmento bancário.

Assim, nota-se que essas gerações apresentam características específicas no que se refere à inovação e à busca por soluções práticas e econômicas, e este estudo tem por objetivo investigar algumas delas, com intuito de fornecer informações sobre esse novo perfil de consumidores. Compreender a influência subjacente à adoção de serviços de fintechs pelas gerações entrantes do mercado financeiro, adicionalmente auxiliaria os bancos tradicionais a atenderem, no futuro, à demanda dessas gerações. Sendo assim, investigar como as gerações podem influenciar nesses modelos de negócio, como as características individuais têm capacidade de interferir na iniciativa de utilização dessas empresas, e quais fatores se sobressaem no que se refere à intenção de uso (atitude) por consumidores, ou prováveis consumidores, desse tipo de negócio, torna-se relevante, já que a previsão sobre o comportamento dos consumidores é habilidade essencial ao mercado de produtos e serviços. Desse modo, questiona-se: qual o impacto que variáveis inerentes a esses indivíduos e às suas percepções teriam sobre a intenção de uso de serviços de fintechs?

Considerada um construto psicológico latente, atitude é uma avaliação duradoura feita de pessoas, objetos e ideias (ARONSON; WILSON; AKERT, 2002), não devendo ser confundida com opinião. "Atitudes envolvem o que as pessoas pensam, sentem, e como elas gostariam de se comportar em relação a um objeto atitudinal" (RODRIGUES; ASSMAR; JABLONSKI, 2009, p. 85). "Atitude é a expressão do sentimento em relação a algo; enquanto intenção é a propensão declarada a fazê-lo; e comportamento consiste na ação em si" (LUCIAN; DORNELAS, 2015, p. 159). Ou seja, a atitude é a avaliação em relação a algo, enquanto a intenção é a manifestação atitudinal direcionada a algo. Adicionalmente, a teoria do comportamento planejado colabora para o entendimento da intenção atitudinal, ao postular que "o melhor prognosticador do comportamento planejado e deliberado da pessoa é a sua intenção comportamental" (ARONSON; WILSON; AKERT, 2002, p. 159). Portanto, a atitude abrange a intenção de uso, uma vez que um dos componentes da atitude é comportamental, e a intenção é uma inclinação para manifestar um comportamento determinado. 
Neste estudo, teve-se como objetivo investigar a influência de atributos do indivíduo, referentes à inovação, e de variáveis perceptivas sobre a intenção de uso de serviços de fintechs por consumidores brasileiros das gerações $\mathrm{Y}$ e Z, usuários e não usuários dessas empresas startups. Entendemos que a compreensão do impacto de novas tecnologias que proporcionam o surgimento de novos modelos de negócio, como as fintechs, a partir da ótica dos consumidores, torna-se importante para a identificação de quais atributos são considerados mais relevantes por esses consumidores, para, então, buscar atender suas expectativas.

\section{Modelo teórico de pesquisa}

Buscou-se, na literatura, um modelo de previsão de relacionamento entre variáveis baseado no modelo de aceitação de tecnologia proposto por Davis (1989), ou Technology Acceptance Model (TAM), que embora proponha relações entre variáveis que produzem como desfecho o comportamento de adoção da tecnologia, agrega a intenção atitudinal de uso, variável que o presente trabalho visa explicar. O modelo TAM já foi amplamente testado com diferentes amostras e em diferentes situações, tendo se provado um modelo válido e confiável para explicar a aceitação e uso dos sistemas de informação (DAVIS; VENKATESH, 1996; HU et al., 2019; FEATHERMAN; PAVLOU, 2003). Além disso, buscava-se um modelo que também contivesse variáveis que a presente pesquisa tem interesse, relacionadas à inovação e risco, razões que explicam a escolha do modelo preditivo e do instrumento de Chauhan, Yadav e Choudhary (2019) como base de inspiração.

Durante a busca na literatura por modelos que explicassem a intenção de uso de uma determinada tecnologia, foram encontrados modelos como os de Pikkarainen et al. (2004), Venkatesh e Davis (2000), Wang et al. (2003) e Suh e Han (2002), todos baseados no modelo TAM e interessados no uso do internet banking como objeto de estudo. Porém, estes modelos não reuniam as variáveis e relações que pretendem ser analisadas pelo presente estudo, referentes à inovação e à percepção de risco, algo que só foi encontrado no modelo preditivo de Chauhan, Yadav e Choudhary (2019).

O modelo de Chauhan, Yadav e Choudhary (2019) consiste na inserção das variáveis Inovatividade Inata, Domínio da Inovação Específica e Risco de Segurança Percebido ao modelo TAM original (DAVIS, 1989), contudo, destina-se apenas ao entendimento da intenção de uso, excluindo a variável comportamento de uso do modelo TAM. O modelo dos autores supracitados foi validado com consumidores indianos, no intuito de identificar o impacto da inovação e do risco percebido, além das variáveis já propostas pelo modelo TAM, quais sejam, utilidade e facilidade de uso percebidas, na intenção de uso de internet banking.

O objeto do presente estudo, as fintechs, não é o mesmo daquele utilizado na bibliografia encontrada, o internet banking. Entretanto, fintechs configuram também uma ferramenta tecnológica, por isso, utilizou-se como base o modelo dos autores indianos, com alterações no que se refere: a) à retirada de uma das variáveis - a atitude -, por questões conceituais adotadas nessa pesquisa; b) à inclusão de itens no instrumento de pesquisa, com o intuito de fornecer uma melhor compreensão dos indicadores, e; c) à apresentação gráfica do modelo teórico (Figura 1) distinta do modelo indiano no qual foi inspirado, com vistas a apresentar as relações previstas de uma forma linear, na qual seja possível visualizar quais indicadores antecedem os outros, para colaborar na compreensão das relações de predição do modelo. 
A construção desse modelo teórico fundamentou-se na formulação mais consistente do relacionamento causa-efeito entre variáveis, na qual as correlações entre as variáveis são determinadas por meio do conhecimento prévio dos autores e de possíveis inter-relações apresentadas em modelos já existentes na literatura (SOUZA, 2013). O modelo teórico que é apresentado no estudo em tela, inspirado no modelo de Chauhan, Yadav e Choudhary (2019), difere deste último no que tange ao reposicionamento de suas variáveis no diagrama estrutural do modelo e à exclusão da variável atitude, uma vez que o modelo da presente pesquisa já aborda a intenção comportamental, que é uma atitude direcionada, ou seja, a intenção é uma manifestação da atitude (LUCIAN; DORNELAS, 2015). Manter a variável atitude no modelo o tornaria redundante.

Figura 1 - Modelo teórico da pesquisa

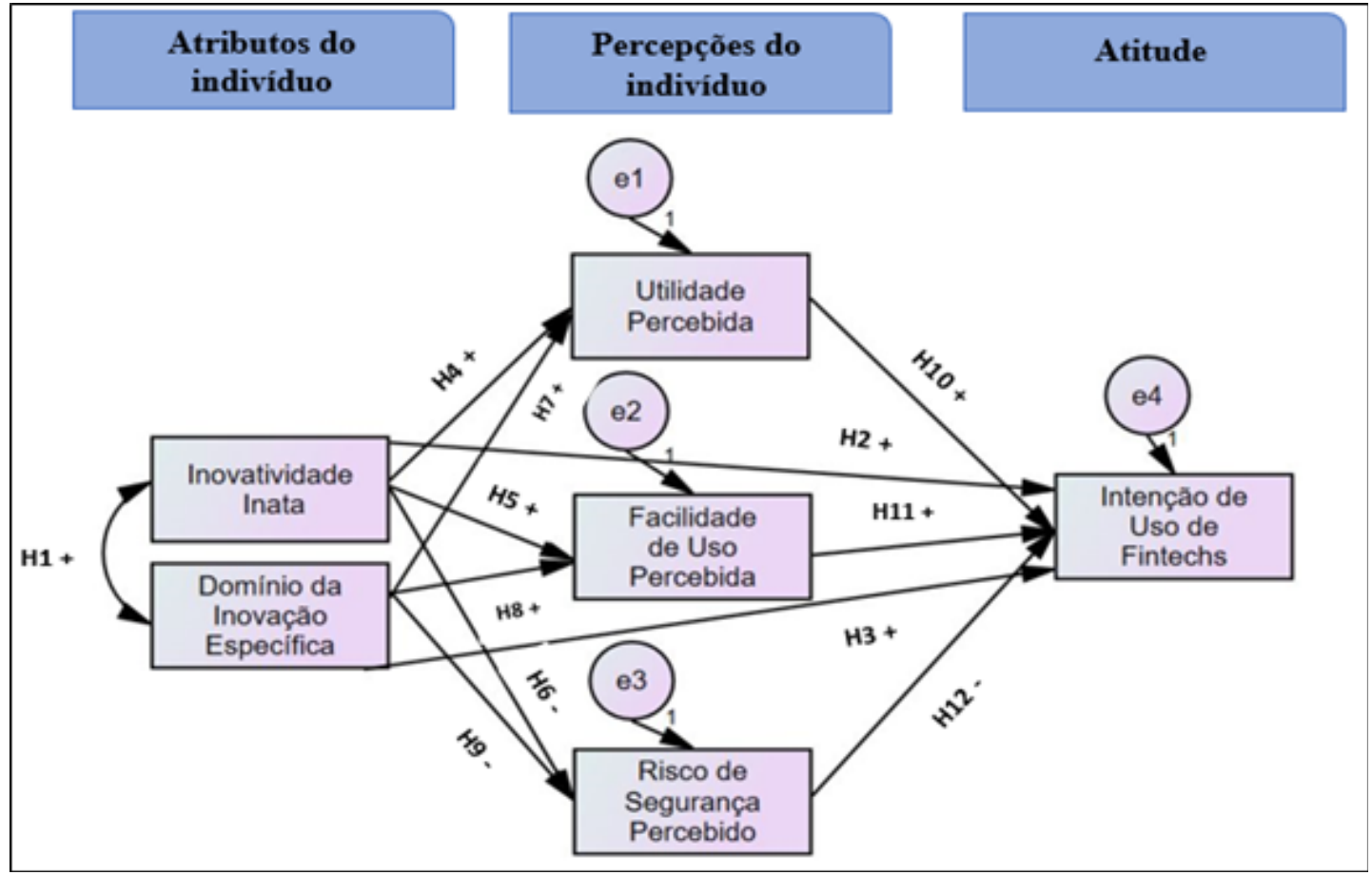

Fonte: Inspirado em Davies (1989).

Outro ponto a ser exposto sobre o modelo da presente pesquisa é que os indicadores Inovatividade Inata e Domínio da Inovação Específica foram tratados, nesta pesquisa, como "atributos do indivíduo"; os indicadores Utilidade, Facilidade de Uso e Risco de Segurança foram abordados como "percepções do indivíduo"; e a Intenção de Uso de Fintechs como "atitude". Esse modelo pretende explicar os impactos das variáveis antecedentes na intenção de uso de serviços de fintechs, por meio de relações diretas e, também, pela influência desses indicadores em conjunto (efeitos diretos e indiretos). Parte-se dos indicadores Inovatividade Inata (II) e Domínio da Inovação Específica (DIE) (correlacionados entre si), os quais foram compreendidos como atributos do indivíduo relativos à inovação, para a verificação de sua influência direta sobre a Intenção de Uso de Fintechs (IUF). Então, observa-se sua influência sobre os indicadores agrupados como percepções do indivíduo, quais sejam, Utilidade (UP), Facilidade de Uso (FUP) e Risco de Segurança (RSP) percebidos no uso de fintechs, que, por conseguinte, impactam na variável consequente Intenção de Uso de Fintechs (IUF), pertencente ao grupo atitude. Além disso, os indicadores agrupados em atributos e percepções do indivíduo, em conjunto, têm sua influência verificada na Intenção de Uso de Fintechs. 
O comportamento inovador dos consumidores desempenha um papel importante na adoção de novos produtos e serviços, pois quanto maior a capacidade de inovação, ou as dimensões de inovatividade, mais frequentes as compras de novos produtos ou a intenção de adoção (LUI; TARRAÇO; PONCHIO; BERNARDES, 2018). No contexto da informação e tecnologia, a inovação seria uma tendência do indivíduo a ser um pioneiro e líder de opinião, pela vontade demonstrada em experimentar novas tecnologias. A inovação do consumidor é crucial, pois reduz o impacto desmotivador da complexidade da inovação tecnológica (CHAUHAN; YADAV; CHOUDHARY, 2019).

Conforme Chauhan, Yadav e Choudhary (2019), estudos anteriores identificaram a inovação do consumidor como um dos principais determinantes da adoção de tecnologias inovadoras, inovação esta que pode ser representada por características individuais consideradas inovadoras, como a "predisposição inovadora" (MIDGLEY; DOWLING, 1993), a "inovatividade global" (GOLDSMITH; FOXALL, 2003), a "inovatividade atualizada" (ROGERS, 2005) e a "inovatividade cognitiva e sensorial" (PARK et al., 2010). Porém, duas características inovadoras se destacam, por serem amplamente utilizadas em vários trabalhos de pesquisa psicológica do consumidor: a "inovatividade inata" e o "domínio da inovação específica" (ROGERS, 2005).

A Inovatividade Inata (II) é uma predisposição das pessoas a adotarem uma inovação, ou seja, as pessoas tenderiam a se comportar de forma diferente em relação a novos produtos, serviços ou ideias, devido às suas diferenças em caráter inovador. II pode produzir efeitos diretos e indiretos na adoção de inovação, pois é um traço de personalidade de ordem superior (CHAUHAN; YADAV; CHOUDHARY, 2019; MIDGLEY; DOWLING, 1978) e constitui uma perspectiva generalista da característica inovadora pela qual se pode analisar um consumidor (KAUSHIK; RAHMAN, 2014).

Evidências de pesquisa em sistema de informação e difusão da inovação mostram que a II influencia positivamente a percepção dos indivíduos em direção a novas tecnologias. Pessoas inerentemente inovadoras são as primeiras a adotá-las, além de serem mais educadas e mais tecnicamente inteligentes do que os menos inovadores ou os adotantes tardios (CHAO; REID; MAVONDO, 2013; JACKSON; YI; PARK, 2013), colaborando para que demonstrem crenças mais positivas em relação a novas tecnologias (PARVEEN; SULAIMAN, 2008).

Medir a inovatividade de forma confiável e válida ainda é um desafio. Muitas pesquisas discutem as métricas mais efetivas, contudo não há ainda uma concordância entre os pesquisadores sobre a totalidade dos aspectos (exógenos e endógenos) que compõem e influenciam consumidores inovativos. Essa circunstância também causa, por parte das empresas, fragilidades nos direcionamentos de recursos e esforços de marketing que objetivam a adoção de novos produtos e serviços (LUI et al., 2018).

Controvérsias também existem, pois a literatura disponível não é consensual quanto à adequação e à força do relacionamento entre II do consumidor e intenção de adoção de novos produtos (IM; MASON; HOUSTON, 2007; LUI et al., 2018). Pesquisadores relataram validade preditiva inferior de características generalistas de inovação em relação ao comportamento de adoção de determinada categoria de produtos, e enfatizaram a superioridade do Domínio da Inovação Específica (DIE) na explicação do comportamento (GOLDSMITH; KIM; FLYNN; KIM, 2005); ou, ainda, a necessidade de apreciar os efeitos conjuntos de Domínio da Inovação Específica (DIE) e Inovatividade Inata (II) (MIDGLEY; DOWLING, 1978). É patente a necessidade de investigação mais aprofundada sobre o poder explicativo de II no contexto da adoção 
de novos produtos e serviços.

Se a perspectiva II está relacionada à disposição ou abertura do consumidor à novidade, a perspectiva de Domínio da Inovação Específica (DIE) aponta para a predisposição do indivíduo em ser o pioneiro no aprendizado e adoção de produtos e serviços inovadores em um domínio específico (LUI et al., 2018; GOLDSMITH; HOFACKER, 1991). Quanto ao DIE, percebe-se que a influência da motivação do indivíduo para prestar atenção em algo também depende da sua personalidade, ou seja, algumas pessoas gostam de pensar mais a fundo nas coisas do que outras; logo, esses indivíduos têm uma maior necessidade de cognição, o que é uma característica que contribui para a inovatividade e pode levar a conhecer uma área específica (ARONSON; WILSON; AKERT, 2002; VARMA CITRIN et al., 2000). Por sua vez, consumidores com perfil mais inovador para determinada classe de produtos e serviços, utilizam produtos mais inovadores e demonstram uma predisposição positiva quanto à inovação e ao uso de novos produtos.

É difícil prever comportamentos a partir de traços de personalidade, pois quanto mais abstrato o traço, menor a capacidade de predição (GOLDSMITH; HOFACKER, 1991), por isso a escala DIE foi desenvolvida baseada em aspectos comportamentais específicos. Desse modo, no modelo teórico da presente pesquisa foram utilizados os indicadores Inovatividade Inata e Domínio da Inovação Específica, os quais foram classificados como atributos do indivíduo. No entanto, o modelo desenvolvido nesta investigação prevê uma correlação desses indicadores, já que os mesmos fazem parte de um conjunto de elementos que podem pertencer à inovação, e em atenção aos apontamentos de Midgley e Dowling (1978) acerca da necessidade de sua apreciação conjunta. Supõe-se que um consumidor que possua uma dessas características, pode possuir a outra, e causar uma influência conjunta na intenção de uso de serviços tecnológicos, como as fintechs.

Neste estudo, os indicadores Utilidade Percebida (UP), Facilidade de Uso Percebida (FUP) e Risco de Segurança Percebido (RSP) são designados como percepções do indivíduo. A Utilidade Percebida (UP) refere-se à probabilidade subjetiva do usuário em potencial de que o uso de uma determinada tecnologia aumente seu desempenho. UP é considerado um grande preditor da intenção dos consumidores para a adoção de tecnologia inovadora, pois aumenta a satisfação, a fidelidade e a retenção comportamental dos consumidores (MARTINS; OLIVEIRA; POPOVIC, 2014; REZAEI; AMIN; MOGHADDAM; MOHAMED, 2016; AMIN; REZAEI; ABOLGHASEMI, 2014).

A Facilidade de Uso Percebida (FUP) é definida como o grau em que um usuário em potencial percebe que, utilizando um determinado sistema, não será preciso esforço para realizar uma tarefa (DAVIS, 1989), sendo considerada uma das características de maior influência na adoção de novas tecnologias (CHAUHAN; YADAV; CHOUDHARY, 2019; DAVIS, 1989; PIKKARAINEN et al., 2004).

Chauhan, Yadav e Choudhary (2019), baseados em vários estudos, relatam que os consumidores inovadores têm mais propensão a adotar inovações tecnológicas por verem menor complexidade nelas do que as outras pessoas, ou seja, por terem mais domínio de entendimento e de uso delas. Além do que, pessoas com comportamento mais inovador utilizarão inovações tecnológicas com menor dispêndio de esforço, causando uma percepção de mais utilidade no seu uso. A Inovatividade Inata se concentra na tendência individual à abertura geral para novas coisas, mais voltada a uma perspectiva sociopsicológica, e pode ter um forte efeito sobre a Utilidade Percebida e a Facilidade de Uso Percebida (LUI et al., 2018). Adicionalmente, a 
percepção de mais utilidade no uso pode ser comprovada (DE LUNA et al., 2017) como uma das variáveis com maior influência sobre a intenção de uso da tecnologia, com um total de $43 \%$ de influência. Pikkarainen et al. (2004) concordam que o uso de um sistema é determinado significativamente pela Utilidade Percebida (UP) e pela Facilidade de Uso Percebida (FUP).

Já o indicador Risco de Segurança Percebido (RSP) é considerado um dos pontos de maior preocupação para os consumidores_e um grande obstáculo para a aceitação de qualquer inovação. O risco percebido é comumente considerado como uma incerteza sentida em relação a possíveis consequências negativas em usar um produto ou serviço (FEATHERMAN; PAVLOU, 2003)._O risco é inerente à inovação e os clientes evitam essas inovações até que possam aprender mais sobre elas. O risco percebido estará em um nível muito alto se a inovação estiver relacionada a serviços financeiros, e sua associação com a internet aumenta ainda mais a percepção de risco (CHAUHAN; YADAV; CHOUDHARY, 2019).

No contexto de internet banking e de serviços online de pagamento, o risco de segurança desempenha um papel importante, pois os consumidores estão preocupados com a segurança em relação ao roubo de informações privadas e em relação à confidencialidade dos dados (CHAUHAN; YADAV; CHOUDHARY, 2019). O grau de risco percebido afeta a confiança dos usuários (HU et al., 2019), o que conduz a um efeito negativo direto do RSP sobre a intenção dos consumidores em adotar serviços eletrônicos financeiros inovadores, como internet banking e fintech (OZDEMIR; TROTT; HOECHT, 2008; MARTINS; OLIVEIRA; POPOVIC, 2014).

Contudo, quando os indivíduos são altamente inovadores, eles podem suportar um considerável grau de incerteza e têm intenção mais positiva de usar a inovação. Em outras palavras, eles estão menos temerosos quanto aos riscos e mais receptivos à inovação tecnológica (HU et al., 2019). A vontade dos indivíduos em adotar novas ideias, disposição para lidar com as incertezas e sua capacidade de assumir riscos são as características mais importantes dos inovadores. O comportamento inovador do indivíduo provê a capacidade de lidar melhor com o risco, pois sua capacidade de lidar com as incertezas reduz sua sensibilidade ao risco (CHAUHAN; YADAV; CHOUDHARY, 2019). Sendo assim, pretende-se verificar se RSP é uma variável importante na intenção de uso de serviços de fintech, no contexto brasileiro. Desse modo, sugerem-se as seguintes hipóteses do modelo de pesquisa:

\section{H1: II e DIE se correlacionam positivamente.}

\section{H2: II influencia positivamente IUF.}

H3: DIE influencia positivamente IUF.

H4: II influencia positivamente UP.

H5: II influencia positivamente FUP.

H6: II influencia negativamente RSP.

H7: DIE influencia positivamente UP.

H8: DIE influencia positivamente FUP.

H9: DIE influencia negativamente RSP. 


\section{H10: UP influencia positivamente IUF.}

\section{H11: FUP influencia positivamente IUF.}

\section{H12: RSP influencia negativamente IUF.}

A direção das hipóteses do modelo teórico de pesquisa consta na Figura 1, com quase todos os relacionamentos previstos com influência positiva e direta. Relações inversas são previstas apenas nas hipóteses H6, H9 e H12, relacionadas às associações entre risco de segurança com os indicadores de inovação (II e DIE) e com a intenção de uso de serviços de fintechs.

\section{Metodologia}

\subsection{Instrumento de pesquisa}

Nesta seção, serão descritas as etapas de preparação do instrumento e seu conteúdo. A primeira parte do instrumento intencionou abordar aspectos referentes ao perfil amostral, questionando os respondentes quanto ao uso de fintechs, regionalidade, idade, sexo e classe socioeconômica, seguindo os critérios da Associação Brasileira de Empresas de Pesquisa (ABEP, 2018). Já a segunda parte, traz os itens que investigam as variáveis de interesse (indicadores) desta pesquisa, dispostos em escala Likert variando de 1 (discordo totalmente) a 5 (concordo totalmente). Para a composição do instrumento, 17 itens foram aproveitados do estudo de Chauhan, Yadav e Choudhary (2019), conforme Tabela 1.

Como esta pesquisa utilizou como base um questionário oriundo de outra língua, foi necessária sua tradução, a qual ocorreu de forma sistemática, conforme as técnicas apresentadas a seguir, além da sua adaptação, que considerou que o instrumento seria aplicado em outra realidade cultural, a qual pode possuir variações linguísticas, diferenças de valores, de cultura, entre outros (CASSEPP-BORGES; BALBINOTTI; TEODORO, 2010). A primeira técnica utilizada para a adequação do instrumento foi a tradução reversa (back-translation), com uso de traduções independentes: a primeira feita por dois bilíngues ou indivíduos com proficiência em inglês, que traduziram o instrumento de pesquisa do inglês para o português; e a segunda realizada por outros dois bilíngues que não participaram da primeira fase, traduzindo do português para a língua original do instrumento - o inglês -, com o objetivo de que a versão retraduzida se aproximasse ao máximo da original, a fim de dificultar que o viés de um tradutor influenciasse a medida. Como decisão oriunda da etapa de tradução reversa, foi feita uma alteração no item II2 por questões de inteligibilidade do mesmo para os respondentes. 
Tabela 1 - Indicadores e itens do modelo de pesquisa após adequações

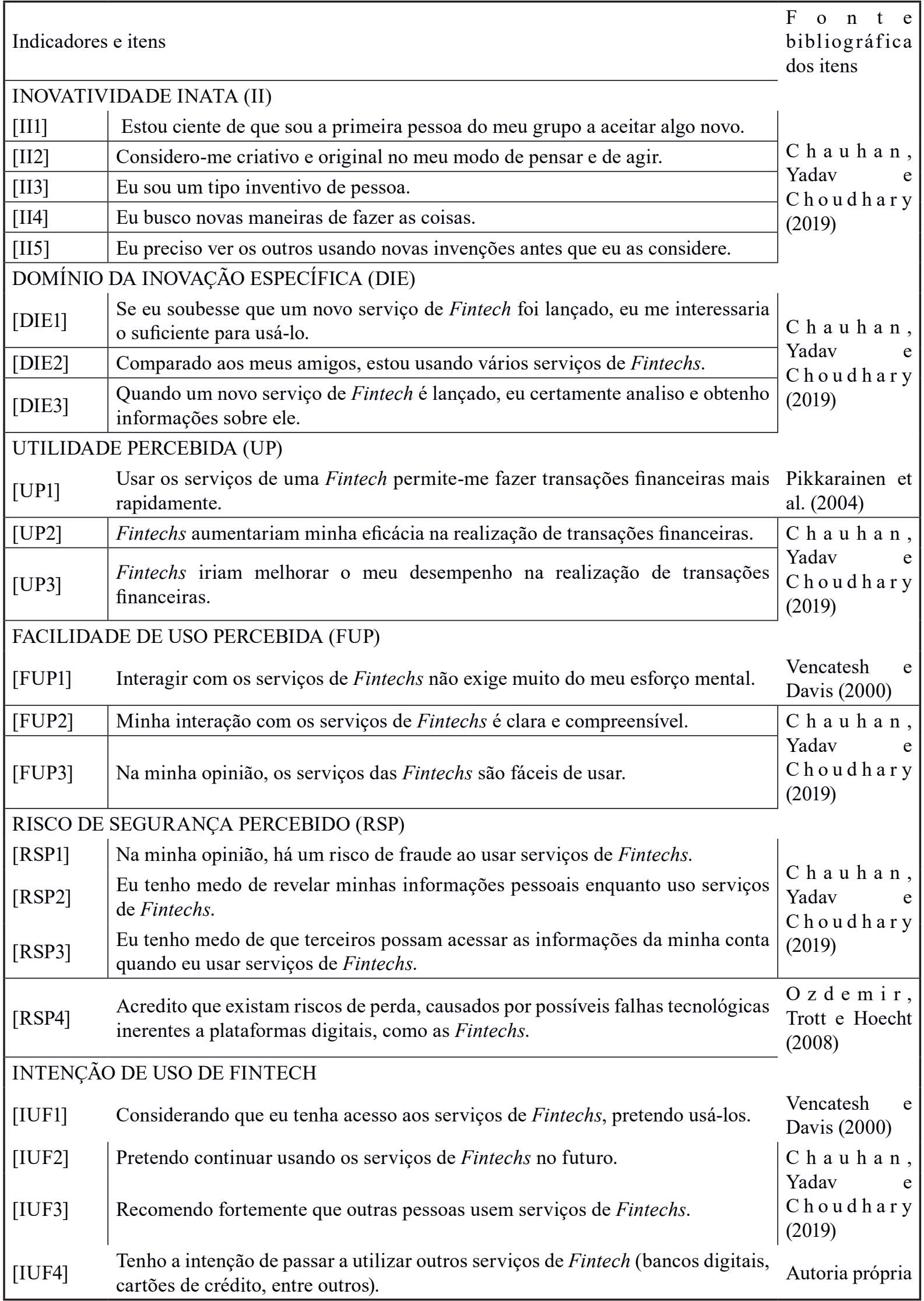


No instrumento de Chauhan, Yadav e Choudhary (2019), foram estabelecidos construtos com menos de três itens. Logo, com o objetivo de aumentar a abrangência da representação das variáveis postuladas pelos autores supracitados, foram acrescentados outros itens encontrados na literatura que também pudessem representar os indicadores, e foi criado um item, com base no referencial teórico. Todos os itens, sejam os originais de Chauhan, Yadav e Choudhary (2019), sejam os de outras fontes bibliográficas, foram adaptados colocando "fintechs" como objeto de avaliação atitudinal. Na Tabela 1, são apresentados os itens do instrumento após todas as adequações.

Para a verificação da validade teórica do instrumento traduzido e da compreensão do questionário como um todo, foi executada análise semântica, que visa verificar se todos os itens são compreensíveis para todos os membros da população a qual o instrumento se destina (PASQUALI et al., 2010). Desse modo, a técnica foi aplicada a três voluntários, escolhidos de acordo com o grau de instrução - ensino médio, superior e pós-graduação - e faixa etária correspondente à população buscada por este trabalho, consumidores brasileiros das gerações Y e Z. Como resultado deste pré-teste teórico do instrumento, foram: melhorados o texto da introdução do questionário e a qualidade da figura utilizada com os exemplos de fintechs; uma pergunta sobre o perfil do respondente foi alterada para "Quanto ao uso de fintechs: já usei, às vezes uso, uso frequentemente ou nunca uso fintechs"; e os itens II2: "Considero-me criativo e original no meu modo de pensar e de agir" e II3: "Eu sou um tipo inventivo de pessoa", foram considerados idênticos pelos avaliadores, o que motivou a exclusão do item II3.

Após a back translation e a análise semântica, foi executado o pré-teste teórico análise de juízes, pela qual peritos da área devem ajuizar se os itens estão se referindo ou não ao indicador em questão. Participaram cinco juízes, sendo três deles da área financeira e dois de psicologia, aos quais foi entregue uma tabela para que agrupassem os itens nos indicadores que eles acreditassem que pertenciam, conforme definição constitutiva dos indicadores constante na tabela entregue. Foi verificada se havia concordância entre os juízes de, no mínimo, $80 \%$ com relação ao indicador ao qual aqueles itens foram distribuídos, para a tomada de decisão sobre a permanência ou não deles no instrumento de coleta (PASQUALI et al., 2010). Como resultado desta etapa, foi excluído o item II5: "Eu preciso ver os outros usando novas invenções antes que eu as considere", por não alcançar o percentual de concordância exigido. Após a aplicação destas técnicas para validar teoricamente o instrumento, o mesmo ficou apto a ser utilizado no contexto brasileiro.

\subsection{Amostra}

A população alvo desta pesquisa consistiu em consumidores brasileiros das gerações $Y$ e Z, usuários e não usuários de fintechs. Howe e Strauss (2007), que desenvolveram uma teoria geracional e postularam o termo Millennials (Geração Y), definem geração como um conjunto de pessoas nascidas num mesmo intervalo de tempo, que coincidem na mesma fase de vida e possuem atributos, cognições e atitudes comuns. A escolha por esta população, além de residir no fato de que são gerações mais tecnológicas e mais predispostas à utilização de startups financeiras, repousa no interesse por quais características desses indivíduos têm influência na intenção de uso de serviços de fintechs e quais têm mais impacto nessa decisão.

A amostragem foi não-probabilística e o cálculo amostral se baseou na necessidade de 10 sujeitos para cada item do instrumento (PASQUALI et al., 2010), para a definição do quantitativo mínimo exigido para compor a amostra, qual seja, 200 participantes válidos, consi- 
derando-se que o instrumento desta pesquisa possui 20 itens. Ademais, 200 é um N mais recomendável quando se pretende utilizar técnicas estatísticas mais sofisticadas (BYRNE, 2016). A aplicação do questionário obteve amostra de 304 respondentes que, após a limpeza do banco de dados quanto a outliers, resultou em uma amostra de 297 respondentes válidos.

Após a limpeza do banco de dados, iniciou-se os procedimentos para a caracterização da amostra. Quanto ao uso de fintechs, foi feito um agrupamento para a identificação de usuários e não usuários desta tecnologia. A alternativa "nunca usei" (40,7\% dos respondentes) foi classificada como o grupo de "não usuários" e as alternativas "já usei, mas não uso mais" (4,4\%), "uso pouco" (32\%) e "uso bastante" (22,9\%) foram agrupadas como "usuários", totalizando 59,3\% dos respondentes. No que se refere à distribuição da amostra por sexo, $53,9 \%$ dos respondentes era do sexo feminino e $46,1 \%$ do sexo masculino.

A idade dos respondentes foi um fator delimitado pela população de pesquisa - sujeitos das gerações Y e Z -, por isso o mínimo foi de 18 e o máximo de 39 anos ( $m=26$ anos; $d p=$ 5,94). A regionalidade dos indivíduos não foi distribuída de forma homogênea, porém houve participantes de todas as regiões brasileiras, predominando o Nordeste $(74,7 \%)$. Quanto à classe social, observou-se que a maior parte, referente à junção das classes D-E, C2 e C1, percebe uma renda média até $\mathrm{R} \$ 2.965,69$, correspondendo a $62,3 \%$ da amostra. Os $37,7 \%$ restantes correspondem à junção das classes B2, B1 e A, com renda média acima de $\mathrm{R} \$ 5.363,19$.

O nível de escolaridade superior incompleto ou acima representou a maior parte da amostra (84,5\%). A maioria da amostra apresenta uma fonte de renda que provem de trabalho formal $(52,2 \%)$ ou de trabalho informal $(20,5 \%)$, enquanto o restante não está trabalhando (27,3\%). Quando indagados quanto à busca por informações sobre inovação, inclusive na área financeira, a maioria $(65,3 \%)$ respondeu positivamente, assim como foi alto o percentual de sujeitos $(93,6 \%)$ que declararam que inovações podem contribuir na sua organização financeira. Por fim, no que se refere à intenção de uso de serviços de fintechs, $81,8 \%$ dos sujeitos afirmaram sua intenção de utiliza-los, pelo menos uma vez este ano.

\subsection{Procedimentos de coleta e análise dos dados}

Este é um estudo correlacional, de natureza quantitativa, com finalidade explicativa, segundo a qual a compreensão de um fenômeno é alcançada por meio de explicações das relações entre variáveis. Foi realizado um levantamento amostral (survey) transversal, com coleta dos dados totalmente online, com usuários e não usuários de serviços de fintechs, em um período definido (agosto a outubro/2019). Para isso, o questionário foi construído no site de Formulários Google e disponibilizado por meio de um link personalizado. A amostra foi abordada por meio da divulgação do questionário online em redes sociais (Whatsapp, Instagram, Facebook e E-mail), buscando atingir um público elevado, distinto e de várias localidades. O convite ao estudo não impunha tempo limite de preenchimento do formulário.

Os dados coletados foram submetidos à análise exploratória no software IBM SPSS Statistics v.20, com intuito de identificar erros de digitação e dados faltosos, e também pela verificação da existência ou não de outliers univariados e multivariados, garantias contra resultados inconsistentes usando a Path Analysis (SOUZA, 2013). Foram encontrados sete sujeitos outliers multivariados nos itens do instrumento, os quais foram excluídos do banco, o que resultou numa amostra final de 297 respondentes válidos, superando a amostra desejada de 200 sujeitos. Foram aplicadas estatísticas descritivas (medidas de tendência central, dispersão e frequência), visando 
à caracterização do perfil amostral. Por fim, foi verificado se os dados atendiam aos testes de pressupostos básicos (normalidade, linearidade, homocedasticidade e multicolinearidade) para que fossem considerados aptos a passar pela técnica Path Analysis.

Após a análise exploratória, partiu-se para as análises de propósito correlacional. Foi feita a correlação de Pearson $(r)$ para determinar as covariações entre variáveis, consistindo numa exploração inicial dos dados para posterior execução da Path Analysis. Na sequência, foi executada a técnica Path Analysis no software AMOS v. 22, para que fossem testadas as hipóteses e, consequentemente, determinada a configuração do modelo estrutural final (modelo empírico), com base no modelo teórico apresentado neste estudo. Optou-se pela utilização da Path Analysis devido ao fato de a técnica consistir em averiguação de modelos preditivos/ explicativos de relação entre variáveis, pelo desdobramento das correlações em efeitos diretos e indiretos, o que permite verificar a configuração de um modelo por completo com uso de equações múltiplas, e não apenas as relações bivariadas. Logo, além dela verificar relações diretas, permite verificar o impacto das variáveis em conjunto (relações diretas e indiretas) na variável de desfecho.

Como esta técnica estatística acolhe variáveis diretamente observadas (PILATI; LAROS, 2007), recorreu-se à estratégia de agregação de itens por meio de parcelamento (ZAMBALDI; COSTA; PONCHIO, 2014). Parcelamento se refere a agregar itens individuais em uma ou mais "parcelas" para usar essa(s) parcela(s), em vez dos itens, como o(s) indicador(es) do construto latente de interesse (MATSUNAGA, 2008). Se a estrutura psicométrica for adequada, é possível formar a medida agregada extraindo valores médios aritméticos simples no conjunto de itens (ou seja, extraindo os valores médios dos escores de cada respondente aos itens componentes de um conjunto/parcela de itens). Este recurso produz escores médios observados que podem ser usados em diagramas de Path Analysis. O parcelamento estabiliza as estimativas de parâmetros e também melhora o ajuste do modelo, comparativamente a usar as variáveis observadas originais (itens) no modelo estrutural. Nesta pesquisa, os indicadores utilizados são parcelas de item de II, DIE, UP, FUP, RSP e IUF. Os alfas de Cronbach destas parcelas, assim como as correlações inter-item, foram estimados para verificar sua consistência interna.

A execução da Path Analysis ocorreu em duas etapas (SOUZA, 2013): primeiramente, foi construído um diagrama de trajetórias (modelo teórico), que é útil para postular graficamente o padrão de relações pretendidas, segundo as hipóteses de pesquisa; posteriormente, foram verificados os coeficientes de trajetória, indicando o efeito direto de uma variável, supostamente tratada como "causa", sobre uma variável tratada como "efeito", apontando o tamanho do poder explicativo entre os indicadores das hipóteses confirmadas.

O modelo teórico da pesquisa foi testado com a entrada da matriz de variância-covariância e adoção do estimador ML (Maximum Likelihood). Por meio dos indicadores de ajuste do modelo, verificou-se se o modelo teórico correspondia ao modelo empírico, ou se seriam necessárias alterações. Para a análise do ajuste do modelo, foram utilizados 3 indicadores: (a) Goodness of Fit Index (Índice de Bondade do Ajuste [GFI]) e (b) Comparative Fit Index (Índice de Comparação do Ajuste [CFI]), para ambos, valores desejados acima de 0,90; (c) Root Mean Square Error of Aproximation (Raiz Quadrada da Média dos Quadrados dos Erros de Aproximação [RMSEA]), com valor desejado até 0,08 (BYRNE, 2016). 


\section{Resultados e discussão}

No modelo teórico testado, foi analisado o poder preditivo das variáveis consideradas como "atributos do indivíduo" quanto à intenção de uso de serviços de fintechs e quanto às variáveis "percepções do indivíduo". As "percepções do indivíduo", por sua vez, foram analisadas como preditoras da "atitude" intenção de uso de serviços de fintechs. E, por fim, as variáveis pertencentes aos grupos "atributos do indivíduo" e "percepções do indivíduo", em conjunto, foram verificadas como preditoras da "atitude" intenção de uso de serviços de fintechs (ver Figura 1).

O teste empírico do modelo teórico resultou em ajuste aquém do recomendado pela literatura $[\mathrm{GFI}=0,91, \mathrm{CFI}=0,84$ e RMSEA $=0,325]$. Conforme os indicadores de ajuste e verificação de estimativas das variáveis utilizadas, observou-se que as relações não significativas e com menores pesos padronizados foram aquelas que envolviam o indicador Inovatividade Inata, o que contribuiu para o deficiente ajuste do modelo. Para melhorar o ajuste do modelo, foram necessárias duas alterações: 1) a exclusão do indicador Inovatividade Inata, o qual não apresentou pesos padronizados $(\beta)$ significativos nem com as variáveis "percepções do indivíduo" (UP, FUP e RSP), nem com a variável atitudinal Intenção de Uso de Fintechs e; 2) a imputação de covariância entre os indicadores Utilidade Percebida e Facilidade de Uso Percebida, recomendada pelos índices de modificação do teste do modelo teórico.

Com a exclusão do indicador Inovatividade Inata (II) do modelo teórico, as hipóteses $\mathrm{H} 1, \mathrm{H} 2, \mathrm{H} 4, \mathrm{H} 5$ e $\mathrm{H} 6$ foram refutadas. A variável II apresentou vários percalços durante o planejamento e execução desta pesquisa, desde as fases de pré-teste teórico (Análise Semântica e de Juízes), quando seus itens suscitaram dificuldades de compreensão que culminaram na retirada de dois deles do instrumento, até a fase preliminar de correlação de Pearson, gerando coeficientes de associação fracos com as variáveis UP, FUP e IUF, ou associação nula com RSP.

$\mathrm{Na}$ literatura, alguns estudos apontam resultados promissores relacionados à II. Nos resultados de Chauhan, Yadav e Choudhary (2019), tanto II, quanto DIE, surgiram como os preditores mais significativos das intenções de adoção de internet banking pelos consumidores. E ambas as perspectivas de inovação (II e DIE) tiveram efeito positivo significativo sobre FUP. Essas descobertas implicam que a predisposição dos consumidores para adotar ou usar inovação pode aumentar suas chances de adotar produtos e serviços inovadores porque são mais capazes de percebê-los como sendo mais fáceis de usar, ou podem aprender a usá-los mais rapidamente do que outros tipos de produtos e serviços. Nos resultados de Hu et al. (2019), UP, confiança e a inovatividade do indivíduo têm influências positivas na intenção de adoção de serviços de fintech.

Contudo, em outros estudos a participação da II é duvidosa (IM; MASON; HOUSTON, 2007), ou ao menos não tão decisiva, como exemplificam os resultados de Lui et al. (2018). Com o objetivo de avaliar qual a influência de DIE, II e gênero em comportamento inovador (CI) na experiência de uso com inteligência artificial, detectaram que II, que é uma perspectiva generalista de traço inovador, não é comprovadamente indicadora de previsão de mudança em relação à inovação. Os resultados sugerem que, apesar de haver significância de influência de II em comportamento inovador em usabilidade, este efeito só acontece quando II é baixa; e, notadamente, DIE tem influência maior que II. Nas questões relacionadas a gênero, não houve influência em comportamento inovador na usabilidade, quando moderada por II. Em contrapartida, DIE pode ser um moderador na relação entre gênero e comportamento inovador, em 
termos de acentuada usabilidade de produtos com inteligência artificial por homens.

Talvez, a melhor posição de II nos modelos teóricos que tentam predizer comportamento ou intenção comportamental inovadora, seja a sugerida por Lim e Park (2013), os quais observaram dois fatores importantes na relação entre II, DIE e comportamento inovador: 1) DIE tem um efeito positivo no comportamento inovador e 2) DIE media o impacto de II no comportamento inovador. Esta relação interveniente não foi aventada pelo modelo teórico da presente pesquisa, mas parece fazer sentido, uma vez que uma perspectiva mais generalista e abstrata da inovatividade (II) produziria impacto em comportamentos inovadores através de uma perspectiva mais específica e concreta da inovatividade (DIE).

Após a realização dos ajustes anunciados pelos índices de modificação, obtiveram-se evidências da adequação do modelo empírico, com índices satisfatórios para obtenção de sua confiabilidade $[\mathrm{GFI}=0,99, \mathrm{CFI}=0,99 \mathrm{e} \mathrm{RMSEA}=0,095]$. A Figura 2 apresenta o modelo estrutural final (modelo empírico) do presente estudo, ajustado a partir do modelo teórico (Figura 1). Apesar do indicador RMSEA não ter ficado no limite de 0,08 , considerou-se um resultado aceitável para uma primeira investigação exploratória do modelo teórico desenvolvido nesta pesquisa. O modelo empírico atendeu aos índices desejados com um poder explicativo de $62 \%$ da intenção de uso de serviços de fintechs, capacidade de explicação considerável, haja vista a quantidade de variáveis utilizadas.

As trajetórias previstas pelas hipóteses $\mathrm{H} 3, \mathrm{H} 7, \mathrm{H} 8, \mathrm{H} 9, \mathrm{H} 10$ e $\mathrm{H} 11$ foram confirmadas. Todos os pesos padronizados $(\beta)$ apontam para relações diretamente proporcionais e estatisticamente significativas ( $p<0,05$ ou $p<0,001)$, com exceção do indicador RSP, o qual acusou relação inversa com os indicadores DIE e IUF, conforme previsão do modelo teórico desta pesquisa e como já havia sido antecipado pelas correlações de Pearson. Quanto menor o conhecimento específico sobre inovações, maior a percepção de risco de segurança ao utilizá-las e, por sua vez, menor a intenção de aderir às mesmas, como usar fintechs, por exemplo. Contudo, a trajetória RSP - IUF não foi significativa $(\mathrm{p}=0,08)$, colaborando para a rejeição da hipótese H12.

Os coeficientes de confiabilidade Alfa de Cronbach, e as correlações inter-item, dos indicadores que tiveram suas relações de trajetória confirmadas pelo modelo empírico foram: DIE ( $\alpha=0,77 ; r$ com magnitudes de 0,48 a 0,58$)$; UP ( $\alpha=0,91 ; r$ com magnitudes de 0,68 a 0,89$)$; FUP $(\alpha=0,86 ; r$ com magnitudes de 0,60 a 0,76$)$; RSP $(\alpha=0,87, r$ com magnitudes de 0,50 a 0,78$)$; IUF ( $\alpha=0,89 ; r$ com magnitudes de 0,61 a 0,77$)$. Todos os alfas alcançaram valores aceitáveis, acima de 0,70 (BYRNE, 2016), com destaque para os indicadores FUP e IUF, os quais obtiverem coeficientes de confiabilidade mais altos que aqueles alcançados no estudo de Chauhan, Yadav e Choudhary (2019). As magnitudes das correlações inter-item se mantiveram entre $r=0,48$ e $r=0,89$, com força de relacionamento de moderada a forte. 
Figura 2 - Modelo empírico com pesos padronizados ( $\beta$ )

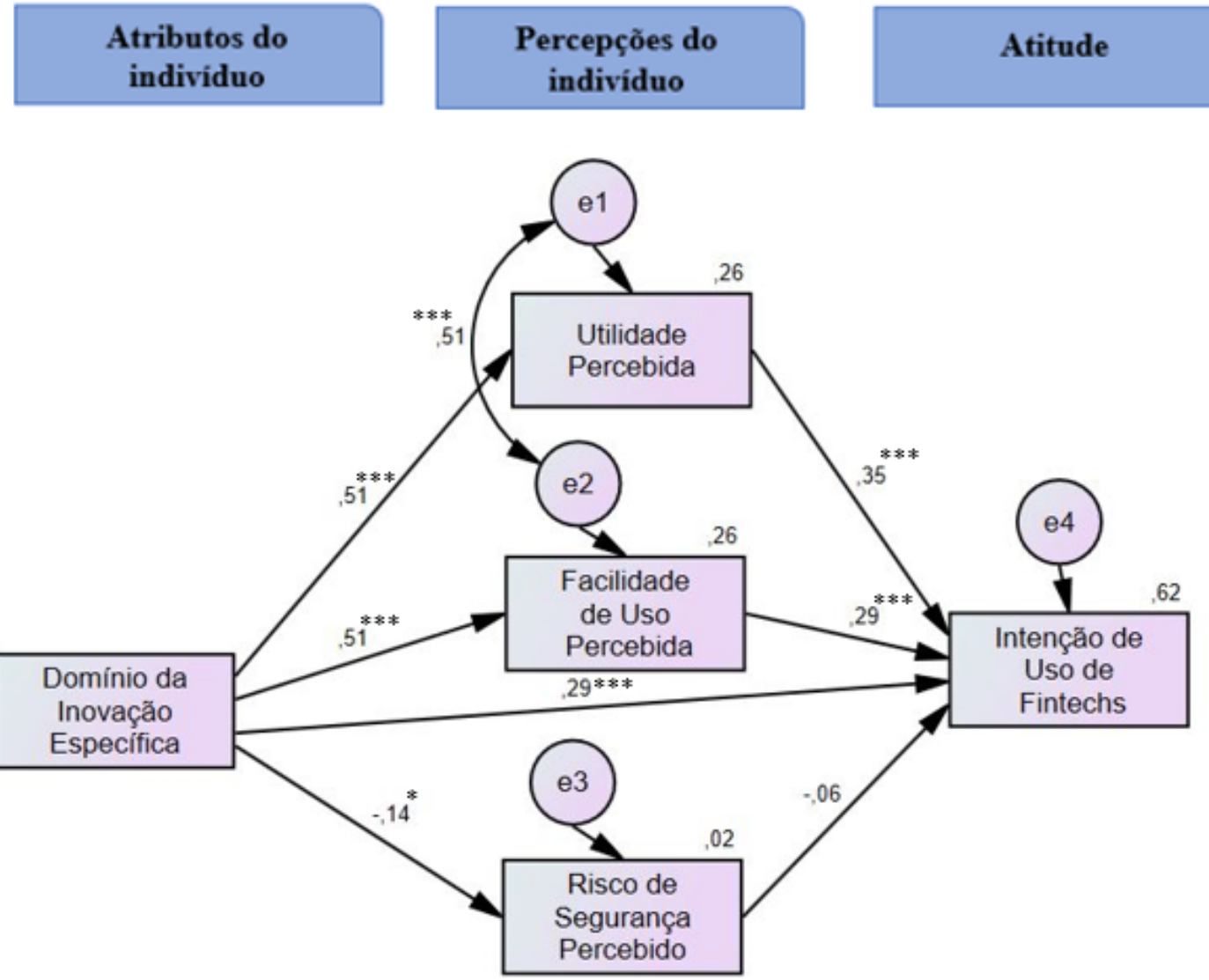

Notas: $* \mathrm{p}<0,05 ; * * * \mathrm{p}<0,001$

Fonte: Dados da Pesquisa.

O fato da variável DIE, que é uma tendência para aprender e adotar novos produtos e serviços dentro de um domínio específico interessado (GOLDSMITH; HOFACKER, 1991), ter permanecido no modelo e ter um impacto significativo na intenção de uso de serviços de fintechs, pode ser verificado na caracterização da amostra, segundo a qual 65,3\% relatam buscar informações na área financeira e 93,6\% acreditam que inovações podem contribuir na sua organização financeira. Logo, verifica-se uma predisposição a buscar informações sobre essas tecnologias, por acreditar que elas podem contribuir na sua organização financeira e, a partir disso, os sujeitos criam uma conscientização financeira que pode ocasionar em um interesse por esse tipo de tecnologia e levar a um domínio dessa inovação específica.

Além do DIE ter permanecido no modelo, ele possui uma influência considerável sobre a percepção de utilidade e de facilidade de uso de serviços de fintechs $(\beta=0,51, p<0,001$ para ambos), assim como também afeta negativamente $\operatorname{RSP}(\beta=-0,14, p<0,05)$. Esse resultado concorda com o estudo de Chauhan, Yadav e Choudhary (2019), no qual DIE também apresenta a mesma relação inversa com RSP, reduzindo significativamente a percepção de risco que os consumidores indianos têm em relação à adoção de internet banking.

Por sua vez, os indicadores de percepção UP e FUP são os que mais influenciam na intenção de uso de serviços de fintechs, prevalecendo a contribuição explicativa de Utilidade Percebida $(\beta=0,35, \mathrm{p}<0,001)$. O fato destes indicadores (UP e FUP) precisarem ser correlacio- 
nados para o modelo empírico ser considerado válido corrobora com a literatura, por exemplo, quando Pikkarainen et al. (2004) relatam que o uso do sistema é determinado pela utilidade percebida (UP) e pela facilidade de uso percebida (FUP); ou conforme De Luna et al. (2017), que relatam que o fato de um indivíduo dispender de menor esforço para usar tecnologias, ou seja, ter mais facilidade de uso, causa uma percepção de mais utilidade no seu uso, um tipo de relação previsto teoricamente e que foi verificado de forma empírica neste estudo.

No estudo de Chauhan, Yadav e Choudhary (2019), UP também foi uma variável de destaque na intenção de uso de internet banking, o que levou os autores a recomendarem a profissionais de marketing a necessidade de enfatizar a utilidade de adotar internet banking por meio de propagandas e promoções, para que os consumidores possam relacionar o benefício ao uso, além de ressaltarem em suas campanhas publicitárias o quão conveniente é mudar para internet banking.

Mas existem resultados contrários aos efeitos de FUP sobre adoção de serviços de fintechs. O estudo de Hu et al. (2019) aplicou o modelo de aceitação de tecnologia (TAM) para estudar a influência por trás da adoção de serviços de fintechs por usuários de um banco chinês, e detectou que FUP não afeta diretamente as atitudes dos usuários em relação à aceitação de serviços desta natureza. Por sua vez, Featherman e Pavlou (2003), em estudo que usou o contexto de serviços de pagamento online, produziu evidências empíricas para medidas de faceta de risco percebido. Seus resultados indicaram que a adoção de serviços eletrônicos é adversamente afetada, principalmente, pela percepção de risco baseado em desempenho, e que facilidade de uso percebida do serviço eletrônico (FUP) reduz essas preocupações de risco. FUP reduz, especialmente, preocupações de risco de desempenho, ainda que apenas indiretamente reduza o risco percebido nas demais facetas de risco.

Curiosamente, a percepção de risco de segurança não afeta a intenção de uso de serviços de fintechs $(\beta=-0,06, p=0,08)$. Todavia, ainda que a trajetória entre RSP e IUF não tenha sido estatisticamente significativa nesta pesquisa, RSP é um indicador indispensável ao bom ajuste do modelo preditivo como um todo, o que sugere que esta variável produz um efeito de mediação nas relações explicativas de IUF (EDWARDS; LAMBERT, 2007).

A literatura sobre o papel do risco na determinação de comportamentos inovadores não é conclusiva. Ora a percepção de risco influencia significativa e negativamente a intenção dos consumidores em adotar serviços bancários pela internet (CHAUHAN; YADAV; CHOUDHARY, 2019); ora a percepção de risco não se relaciona à atitude de aceitação do serviço de fintechs (HU et al., 2019). Estes últimos pesquisadores encontraram um papel indireto dos efeitos do risco sobre a intenção de utilizar serviços de fintechs, pois que o risco percebido poderia afetar as atitudes dos usuários por meio de sua confiança nos serviços da fintech. O mecanismo é que o risco percebido tem um impacto significativamente negativo na confiança, enquanto a confiança ativamente orienta os usuários a se envolverem com esse novo tipo de empresa. Já que o risco percebido tem um papel importante na redução do nível de confiança, instituições financeiras que fornecem serviços de fintech precisam adotar medidas para reduzir o risco percebido pelos usuários, de modo a fortalecer a confiança nos produtos e serviços, e aumentar a disposição dos usuários de empregar os serviços.

Talvez o problema com a relação de predição não significativa de RSP, no presente estudo, tenha sido a falta de especificidade desse risco. Hu et al. (2019) sinalizam como limites aos seus resultados quanto ao RSP a premência de analisar várias dimensões de risco, como riscos 
financeiros, riscos de privacidade e de cibersegurança, na expectativa de melhorar o poder explicativo da noção de risco sobre a adoção de inovações. Um estudo que decompôs a medida geral de risco percebido em facetas de risco, para verificar sua eficiência explicativa dentro do modelo de aceitação de tecnologia (TAM), foi o de Featherman e Pavlou (2003), os quais propuseram que o risco percebido compreende as facetas de (1) desempenho, (2) financeiro, (3) tempo, (4) psicológico, (5) social, (6) privacidade e (7) risco geral. Encontraram que facetas de risco relacionadas ao desempenho (risco de tempo, risco de privacidade, risco financeiro) provaram ser as preocupações mais salientes no contexto de adoção do serviço eletrônico, sobressaindo-se o risco de privacidade como um importante inibidor de comportamento.

Apesar destes apontamentos referentes a relações diretas de determinação no modelo, pondera-se que o poder de explicação alcançado pelo modelo empírico (62\%) se deve ao fato da técnica Path Analysis analisar o impacto das variáveis tanto de forma direta, quanto indireta (efeitos diretos, indiretos e total das variáveis empregadas), por isso a importância da verificação dos indicadores GFI, CFI e RMSEA, pois são os responsáveis por definir se o modelo inteiro é válido. Desse modo, o objetivo da pesquisa de verificar a influência de atributos do indivíduo referentes à inovação e de variáveis perceptivas sobre a intenção de uso de serviços de fintechs por consumidores brasileiros das gerações $\mathrm{Y}$ e Z, usuários e não usuários dessas plataformas, foi alcançado, produzindo um modelo explicativo viável.

No Brasil, está acontecendo uma movimentação da riqueza do país que, conforme ABFINTECHS; PWC (2018), será transferida dos baby boomers para a geração Y (Millennials) até meados deste século. No país, existe uma parcela significativa de jovens, indivíduos que utilizam smartphones e redes sociais de forma intensiva e que esperam soluções práticas e conexões diretas, ou seja, o foco dessa geração está em soluções práticas como, por exemplo, facilidade de uso (FUP) e utilidade (UP), talvez até em detrimento do risco de segurança (RSP). A geração Y é descrita como impaciente, composta por jovens que estão sujeitos a tomar decisões precipitadas (GONÇALVES, 2019; PORTES, 2009), logo, podem não apresentar um limiar mais sensível aos riscos de segurança.

É plausível esperar que as novas gerações apresentem características específicas no que se refere à inovação e à busca por soluções práticas, comparativamente aos baby boomers. Percebe-se que as fintechs estão correspondendo, principalmente, às demandas por oferta de serviços dessas gerações entrantes ( $\mathrm{Y}$ e Z ), as quais buscam informações sobre inovações na área financeira e, por conseguinte, também objetivam que essas inovações contribuam para sua organização financeira, o que pode ser considerado como força impulsionadora no atual desenvolvimento dessas empresas tecnológicas (GAI; QIU; SUN, 2018). Carlin, Olafsson e Pagel (2017) apuraram que a expectativa de vida e a obtenção de conhecimento financeiro têm influências importantes sobre a intenção comportamental de adoção de fintechs pela geração Millennials.

Os consumidores das gerações Y (Millennials) e Z (Digital Natives) estão produzindo revoluções no formato e oferta dos serviços financeiros, pois são grandemente responsáveis pelo aumento do consumo das TICs, pela pressão por redução de custos dos produtos, assim como pela progressiva digitalização dos serviços financeiros. Ou seja, é um perfil que pode ser alcançado pelas fintechs, já que um dos seus pontos fortes está nos baixos custos, uma das características buscadas por esses novos ingressantes do mercado, e isso pode impulsionar ainda mais o crescimento desse modelo de negócios (OLIVEIRA; DESIDÉRIO, 2018). 


\section{Conclusão}

Este estudo voltou-se aos consumidores brasileiros das gerações $\mathrm{Y}$ e Z, questionando qual o impacto que características inovadoras e percepções quanto à experiência de uso teriam sobre a intenção de utilização de serviços fornecidos por fintechs. Sinteticamente, um dos fatores relevantes apresentados por este trabalho foi referente ao indicador Inovatividade Inata, que se mostrou incipiente para explicar a intenção de uso de serviços de fintechs, o que tornou necessária sua exclusão do modelo. Desse modo, no que se refere às relações previstas para esse indicador, elas foram comprometidas, sendo refutadas pela sua exclusão.

$\mathrm{O}$ indicador Inovatividade Inata tem um forte viés sociopsicológico, por retratar características disposicionais de indivíduos que orientam uma abertura para novidades em geral (LUI et al., 2018). Goldsmith e Hofacker (1991) já alertavam para a dificuldade de prever comportamentos a partir de traços de personalidade, em função do nível de abstração do conteúdo a ser representado pelos itens de uma escala de medida, e a alta probabilidade de insuficiente cobertura do traço latente pela descrição operacional (PASQUALI et al., 2010). Talvez o construto Inovatividade Inata ainda não esteja apropriadamente representado pelos itens disponíveis na literatura de tecnologias inovadoras.

O modelo empírico apontou uma correlação entre Utilidade Percebida (UP) e Facilidade de Uso Percebida (FUP), não prevista no modelo teórico desta pesquisa, baseado em Chauhan, Yadav e Choudhary (2019), porém ventilada por alguns autores como Pikkarainen et al. (2004) e De Luna et al. (2017). É plausível a variância compartilhada entre UP e FUP para explicar a Intenção de Uso de Fintechs (IUF), uma vez que pessoas que atribuem utilidade às fintechs e que não entendam seu uso como algo complicado, provavelmente são as que mais se inclinariam a utilizar estes novos modelos de negócios. Tratam-se de achados que podem ser utilizados estrategicamente para alavancar os negócios destas empresas, uma vez que pessoas que dominam inovação, que atribuem utilidade e facilidade de manuseio a serviços eletrônicos como os de fintechs, são aquelas que provavelmente estariam mais susceptíveis ao seu uso, logo, o mercado alvo destas empresas.

Outra questão verificada neste trabalho refere-se ao indicador Risco de Segurança Percebido (RSP), que embora tenha estabelecido a relação inversa prevista no modelo teórico, não foi expressivo para determinar a intenção de uso de serviços de fintechs. Então, para os participantes deste estudo, usuários e não usuários destas empresas financeiras tecnológicas, o que determina fundamentalmente a inclinação ao uso é sua utilidade e facilidade de uso.

Desse modo, foi possível verificar os indicadores de maior influência na intenção de uso de serviços de fintechs para esses consumidores. Isso proporciona implicações tanto acadêmicas, quanto gerenciais, pois a criação de um modelo explicativo, testado no contexto nacional com um objeto relativamente novo nesse contexto, pode ser o primeiro passo para futuras pesquisas nesta linha, além de apontar um caminho a seguir. Como implicações gerenciais, pode-se verificar, a partir do modelo empírico e do estudo como um todo, as características dessa população e quais variáveis têm mais impacto na intenção de uso de serviços de fintechs, tanto por usuários, quanto por não usuários das gerações Y e Z. A partir disso, é possível montar estratégias para aumentar o alcance de mercado, principalmente desse público, por meio daqueles indicadores que têm mais influência e que podem ser melhorados pelas empresas, como demonstrar a utilidade do seu produto e o desenvolvimento de serviços mais acessíveis no que se refere à facilidade de manuseio, por exemplo. 
Frente ao conjunto de achados da pesquisa, acredita-se que o objetivo geral de verificar a influência de atributos do indivíduo, referentes à inovação, e de variáveis perceptivas sobre a intenção de uso de serviços de fintechs foi alcançado, por meio da geração de um modelo explicativo baseado no modelo teórico da pesquisa, produzindo uma solução satisfatória tanto teoricamente, quanto empiricamente, haja vista seus indicadores de ajuste. No que tange às limitações da pesquisa, apresentam-se os seguintes pontos: 1) não foi feito estudo empírico de validades interna e externa (nomológica, convergente e discriminante), apenas a verificação da validade teórica (validade de conteúdo e face validity) dos fenômenos de interesse (ZAMBALDI; COSTA; PONCHIO, 2014); 2) foram escolhidos apenas dois indicadores para representar a inovação, por serem descritos como os mais utilizados na literatura estrangeira (CHAUHAN; YADAV; CHOUDHARY, 2019); 3) o indicador Risco de Segurança Percebido foi representado por itens de teor genérico, em detrimento da investigação de facetas específicas de risco (HU et al., 2019; FEATHERMAN; PAVLOU, 2003); e 4) algumas regiões brasileiras foram subrepresentadas.

Como sugestão para futuras pesquisas, aponta-se a necessidade de estudo de validação transcultural das escalas utilizadas para a realidade brasileira (CASSEPP-BORGES; BALBINOTTI; TEODORO, 2010). Estudos comparativos de grupos também poderiam fornecer informações úteis para o mercado financeiro, assim como a utilização de outras variáveis desfecho, a exemplo da investigação do comportamento efetivo de uso de serviços de fintechs.

Por fim, os achados desse trabalho têm implicações práticas tanto no que se refere ao campo acadêmico, quanto ao mercado, pois reúnem um conjunto de informações acerca de fintechs e de usuários e potenciais usuários desse tipo de serviço. Ainda assim, entender as novas tecnologias que estão sendo rapidamente incorporadas ao cotidiano das pessoas, e as mudanças atitudinais e comportamentais que impulsionam e são impulsionadas pelas inovações tecnológicas, deve não somente colaborar para a promoção de desenvolvimento econômico de agentes do mercado, mas, principalmente, para o desenvolvimento humano e das sociedades.

\section{Referências}

ABEP. Critério de Classificação Econômica Brasil 2018. Disponível em: http://www.abep. org/criterio-brasil Acesso em: 19 mai. 2019.

ABFINTECHS; PWC. Pesquisa Fintech Deep Dive 2018. Disponível em: https:// www.pwc.com.br/pt/setores-de-atividade/financeiro/2018/pub-fdd-18.pdf Acesso em: 12 mai. 2019.

AMIN, M.; REZAEI, S.; ABOLGHASEMI, M. User satisfaction with mobile websites: the impact of perceived usefulness (PU), perceived ease of use (PEOU) and trust. Nankai Business Review International, v. 5, n. 3, p. 258-274, 2014.

ARONSON, E.; WILSON, T. D.; AKERT, R. M. Psicologia Social. 3. ed. Rio de Janeiro: Livros Técnicos e Científicos S.A. - LTC Editora, 2002.

BYRNE, B. M. Structural equation modeling with AMOS: Basic concepts, applications, and programming (Multivariate Applications Series). 3. ed. Ottawa: Routledge, 2016. 
CARLIN, B.; OLAFSSON, A.; PAGEL, M. Technology adoption across generations: financial fitness in the information age. Working Paper Series. National Bureau of Economic Research: Cambridge, UK, 2017.

CASSEPP-BORGES, V.; BALBINOTTI, M. A. A.; TEODORO, M. L. M. In: PASQUALI, L.; COLABORADORES. Instrumentação Psicológica: fundamentos e práticas. 2010. Cap, v. 8, p. 165-198. Porto Alegre: Artmed, 2010.

CHAUHAN, V; YADAV, R;CHOUDHARY, V. Analyzing the impact of consumer innovativeness and perceived risk in internet banking adoption: A study of Indian consumers. International Journal of Bank Marketing, v. 37, n. 1, p. 323-339, 2019.

CHAO, C. W.; REID, M.; MAVONDO, F. Global consumer innovativeness and consumer electronic product adoption. Asia Pacific Journal of Marketing and Logistics, v. 25, n. 4, p. 614-630, 2013.

DAVIS, F. D. Perceived usefulness, perceived ease of use, and user acceptance of information technology. MIS Quarterly, v. 13, n. 3, p. 319-340, 1989.

DAVIS, F. D.; VENKATESH, V. A critical assessment of potential measurement biases in the technology acceptance model: three experiments. International journal of human-computer studies, v. 45, n. 1, p. 19-45, 1996.

DE LUNA, I. R.; MONTORO-RIOS, F.; LIÉBANA-CABANILLAS, F.; DE LUNA, J. G. Aceitação da tecnologia NFC para pagamentos móveis: Uma perspectiva brasileira. RBGNRevista Brasileira de Gestão de Negócios, v. 19, n. 63, p. 82-103, 2017.

EDWARDS, J. R.; LAMBERT, L. S. Methods for integrating moderation and mediation: a general analytical framework using moderated path analysis. Psychological Methods, $v .12, n$. 1, p. 1-22, 2007.

FEATHERMAN, M. S.; PAVLOU, P. A. Predicting e-services adoption: a perceived risk facets perspective. International Journal of Human-Computer Studies, n. 59, p. 451-474, 2003.

FINTECHLAB. Radar Fintechlab 2017: Report Fintechlab Brasil. 2017. Disponível em: http://fintechlab.com.br/wp-ontent/uploads/2017/02/Report FintechLab 2017.pdf Acesso em: 22 jul. 2018.

FRIÓSI, J. F.; CARRARO, N. C.; ALBUQUERUQE, A. F.; YOKOYAMA, N. Análise exploratória da inovação bancária brasileira e as tendências para o setor. Revista Gestão Empresarial, v. 1, n. 1, p. 47-57, 2017.

GAI, K.; QIU, M.; SUN, X. A survey on FinTech. Journal of Network and Computer Applications, v. 103, não tem o número p. 262-273, 2018.

GOLDSMITH, R. E.; FOXALL, Gordon R. The measurement of innovativeness. The 
international handbook on innovation. p. 321-330, 2003.

GOLDSMITH, R. E.; HOFACKER, C.E. Measuring consumer innovativeness, Journal of the Academy of Marketing Science, v. 19, n. 3, p. 209-221, 1991.

GOLDSMITH, R. E.; KIM, D.; FLYNN, L. R.; KIM, W. M. Price sensitivity and innovativeness for fashion among Korean consumers. The Journal of social psychology, v. 145, n. 5, p. 501$508,2005$.

GOMBER, P.; KOCH, J.A.; SIERING, M. Digital Finance and FinTech: current research and future research directions. Journal of Business Economics, v. 87, n. 5, p. 537-580, 2017.

GONÇALVES, C. Geração Z no mercado de trabalho. 2019. Gente uma conexão Globosat. Disponível em: https://gente.globosat.com.br/z-no-mercado-de-trabalho/ Acesso em: 29 de jan. de 2019.

HOWE, N.; STRAUSS, W. The next 20 years: how customer and workforce attitudes will evolve. Harvard business review, v. 85, n. 7-8, p. 41-52, 191, 2007.

HU, Z.; DING, S.; LI, S.; CHEN, L.: YANG, S. Adoption intention of Fintech services for bank users: an empirical examination with an extended Technology Acceptance Model. Symmetry, v. 340, n. 11, p. 1-16, 2019.

IM, S.; MASON, C. H.; HOUSTON, M. B. Does innate consumer innovativeness related to new product/service adoption behavior? The intervening role of social learning via vicarious innovativeness. Journal of Academy Marketing Science, v. 35, n. 1, p. 63-75, 2007.

JACKSON, J. D.; YI, M. Y.; PARK, J. S. An empirical test of three mediation models for the relationship between personal innovativeness and user acceptance of technology. Information \& Management, v. 50, n. 4, p. 154-161, 2013.

JORGE, R.R.; URICH, L. G.; JUNGER, A. P.; DE ANDRADE, A. A.; FACÓ, J. F. B. O Ecossistema de Fintechs no Brasil. Revista de Casos e Consultoria, v. 9, n. 3, p. 931, 2018.

KAUSHIK, A. K.; RAHMAN, Z. Perspectives and dimensions of consumer innovativeness: a literature review and future agenda. Journal of International Consumer Marketing, v. 26, n. 3, p. 239-263, 2014.

LIM, H.; PARK, J. S. The effects of national culture and cosmopolitanism on consumers' adoption of innovation: a cross-cultural comparison. Journal of International Consumer Marketing, v. 25, n. 1, p. 16-28, 2013.

LUCIAN, R.; DORNELAS, J. S. Mensuração de atitude: Proposição de um protocolo de elaboração de escalas. Revista de Administração Contemporânea, v. 19, n. 2, p. 157-177, 2015.

LUI, M. C.; TARRAÇO, E. L.; PONCHIO, M. C.; BERNARDES, R. C. Moderação das 
dimensões de inovatividade na experiência de uso de serviços com inteligência artificial. VII SINGEP - Simpósio Interacional de Gestão de Projetos, Inovação e Sustentabilidade, Anais, 2018.

MARTINS, C.; OLIVEIRA, T; POPOVIC, A. Understanding internet banking adoption: a unified theory of acceptance and use of technology and perceived risk application. International Journal of Information Management, v. 34, n. 1, p. 1-13, 2014.

MATSUNAGA, M. Item parceling in structural equation modeling: a primer. Communication Methods and Measures, v. 2, n. 4, p. 260-293, 2008.

MIDGLEY, D. F.; DOWLING, G. R. Innovativeness: the concept and its measurement, Journal of Consumer Research, v. 4, n. 4, p. 229-242, 1978.

MIDGLEY, D. F.; DOWLING, G. R. A longitudinal study of product form innovation: the interaction between predispositions and social messages. Journal of consumer research, v. 19, n. 4, p. 611-625, 1993.

OLIVEIRA, A. J. G.; DESIDÉRIO, L. G. M. Resenha: "FinTech: Desafios da Tecnologia Financeira", coordenado por Ana Perestrelo de Oliveira. Revista de Direito Econômico e Socioambiental, v. 9, n. 2, p. 417-421, 2018.

OZDEMIR, S.; TROTT, P.; HOECHT, A. Segmenting internet banking adopter and nonadopters in the Turkish retail banking sector. International Journal of Bank Marketing, v. 26, n. 4, p. 212-236, 2008.

PARK, J. E.; YU, J.; ZHOU, J. X. Consumer innovativeness and shopping styles. Journal of Consumer Marketing, v. 27, n. 5, p. 437-446, 2010.

PARVEEN, F.; SULAIMAN, A. Technology complexity, personal innovativeness and intention to use wireless internet using mobile devices in Malaysia. International Review of Business Research Papers, v. 4, n. 5, p. 1-10, 2008.

PASQUALI, L.; COLABORADORES. Instrumentação Psicológica: fundamentos e práticas. Porto Alegre: Artmed, 2010.

PIKKARAINEN, T.; PIKKARAINEN, K.; KARIALUOTO, H.; PAHNILA, S. Consumer acceptance of online banking: an extension of the technology acceptance model. Internet Research, v. 14, n. 3, p. 224-235, 2004.

PILATI, R; LAROS, J A. Modelos de equações estruturais em Psicologia: conceitos e aplicações. Psicologia: Teoria e Pesquisa, v. 23, n. 2, p. 205-216, 2007.

PORTES, G. E. P. Geração Y-características e liderança: uma discussão sobre a importância do autoconhecimento no desenvolvimento da confiança e de uma cultura da transparência para estes líderes. VI EPEGE - Encontro Paranaense de Empreendedorismo e Gestão Empresarial, 
Anais, 2009.

REZAEI, S.; AMIN, M.; MOGHADDAM, M.; MOHAMED, N. 3G post adoption users experience with telecommunications services: a partial least squares (PLS) path modelling approach. Nankai Business Review International, v. 7, n. 3, p. 361-394, 2016.

RODRIGUES, A. ASSMAR, E. M. L. JABLONSKI, B. Psicologia Social. 27. ed. revista e ampliada. Petrópolis: Vozes, 2009.

ROGERS, E. M. Diffusion of innovations. 5. ed. New York: The Free Press, 2005.

SOUZA, T. V. Aspectos estatísticos da análise de trilha (path analysis) aplicada em experimentos agrícolas. 2013. 82 f. Dissertação (Mestrado em Estatística e Experimentação Agropecuária) - Universidade Federal de Lavras, Lavras, 2013.

SUH, B.; HAN, I. Effect of trust on customer acceptance of Internet banking. Electronic Commerce Research and Applications, v. 1, n. 3-4, p. 247-263, 2002.

VARMA CITRIN, A.; SPROTT, D. E.; SILVERMAN, S. N.; STEM J., D. E. Adoption of internet shopping: the role of consumer innovativeness. Industrial management \& data systems, v. 100, n. 7, p. 294-300, 2000.

VENKATESH, V.; DAVIS, F. D. A theoretical extension of the technology acceptance model: Four longitudinal field studies. Management science, v. 46, n. 2, p. 186-204, 2000.

WANG, Y.; WANG, Y.; LIN, H.; TANG, T. Determinants of user acceptance of Internet banking: an empirical study. International journal of service industry management, v. 14, $\mathrm{n}$. 5, p. 501-519, 2003.

ZAMBALDI, F.; COSTA, F. J.; PONCHIO, M. C. Measurement in marketing: current scenario, recommendations and challenges. Revista Brasileira de Marketing - ReMark, v. 13, n. 2, p. 1-27, 2014. 